\title{
Simultaneous colonisation of Helicobacter pylori with and without mutations in the 23S rRNA gene in patients with no history of clarithromycin exposure
}

\author{
M Matsuoka, Y Yoshida, K Hayakawa, S Fukuchi, K Sugano
}

\begin{abstract}
Background-It was recently reported that $A$ to $G$ transition mutations at positions 2143 and 2144 in the 23S rRNA gene are associated with clarithromycin resistance in Helicobacter pylori.

Aims-To study the incidence and mechanism of development of clarithromycin resistance by analysing these mutations. Subjects-Eighty two $H$ pylori positive patients who had an endoscopic examination and no history of treatment with macrolide antibiotics.

Methods-Clarithromycin resistance was screened for by polymerase chain reaction-restriction fragment length polymorphism of the $23 S$ rRNA gene coupled with antibiotic susceptibility testing. In clinical isolates with mutations or resistance, mutations in individual colonies were analysed by direct sequencing.

Results-Of the 79 amplicons (DNA fragments amplified by polymerase chain reaction), Alw26I and MboII digestion disclosed the mutation in four (5\%) and one (1\%) respectively. However, the Alw26I cleavage was incomplete in two of the four amplicons, as was the MboII cleavage. Individual colony analysis of the isolates with incomplete cleavage patterns showed the presence of both wild type and mutated strains in the $23 \mathrm{~S}$ rRNA genes.

Conclusions-Both clarithromycin sensitive and resistant strains colonised in some patients with no history of exposure to macrolides. The results suggest that resistant strains may not be formed but selected by clarithromycin administration.

(Gut 1999;45:503-507)
\end{abstract}

Keywords: Helicobacter pylori; clarithromycin resistance; $23 \mathrm{~S}$ rRNA gene; point mutation; mixed strain colonisation

Clarithromycin is one of the most useful antibiotics in eradication of Helicobacter pylori. However, several reports have shown that about $1-10 \%$ of $H$ pylori isolates are resistant to clarithromycin, ${ }^{1-5}$ which may have resulted in the failure of such treatment. ${ }^{6-8}$ Therefore it is important to examine clarithromycin resistance when considering eradication. Versalovic et $a l^{9}$ reported that $\mathrm{A} 2143 \mathrm{G}$ and $\mathrm{A} 2144 \mathrm{G}$ mutations in domain $\mathrm{V}$ of the $23 \mathrm{~S}$ rRNA genes of $H$ pylori, cognate with residues 2058 and
Table 1 Diagnosis and sex of the subjects

\begin{tabular}{lccc}
\hline Diagnosis & Male & Female & Total \\
\hline Gastric ulcer & 16 & 11 & 27 \\
Duodenal ulcer & 13 & 6 & 19 \\
Combined ulcer & 13 & 1 & 14 \\
Gastric cancer & 4 & 1 & 5 \\
Other & 14 & 3 & 17 \\
Total & 60 & 22 & 82
\end{tabular}

2059 in Escherichia coli, are associated with clarithromycin resistance. We therefore studied these mutations in $H$ pylori isolates by polymerase chain reaction-restriction fragment length polymorphism (PCR-RFLP) and direct sequencing in patients with no history of clarithromycin exposure to determine whether clarithromycin resistant strains are formed or merely selected by clarithromycin treatment.

Subjects and methods

SUBJECTS

The subjects comprised 82 patients who were having endoscopic examinations for upper gastrointestinal problems and had no history of treatment with macrolide antibiotics (table 1). Previous antibiotic use was excluded by examining their medical records closely and carrying out a detailed interview. Patients whose history of previous medical treatment or antibiotic use was not certain were excluded. Written informed consent was obtained from the patients and the study was approved by the institution's ethical committee.

\section{BACTERIOLOGY}

$H$ pylori status was examined by conventional culture and histological tests (Giemsa stain). Four biopsy specimens from different parts of the stomach were obtained to detect $H$ pylori infection. $H$ pylori were isolated from gastric biopsy specimens by culturing on Columbia blood agar base (Oxoid, Basingstoke, Hampshire, UK) containing Skirrow's selective supplement (Oxoid) and 7\% fresh horse blood under microaerobic conditions. Clarithromycin sensitivity was evaluated by the agar dilution test. Colony formation at or above a drug concentration of $5 \mathrm{mg} / \mathrm{l}$ was judged as resistant.

PCR METHOD

Separate gastric biopsy specimens (65 patients) were obtained for DNA extraction using a QIAamp tissue kit (Qiagen, Hilden, Germany).

Abbreviations used in this paper: PCR, polymerase chain reaction; RFLP, restriction fragment length polymorphism. 


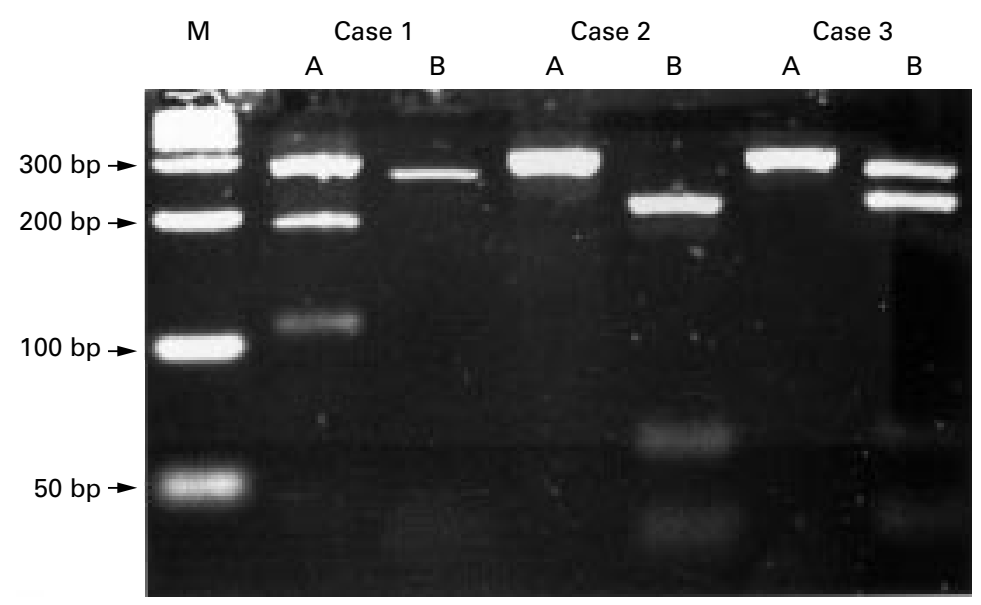

Figure 1 Representative polymerase chain reaction-restriction fragment length polymorphism (PCR-RFLP) pattern of $23 S \mathrm{rRNA}$ genes from patients with clarithromycin resistance. Lane $M, D N A$ size marker; lane $A, P C R-R F L P$ pattern obtained with MboII; lane B, PCR-RFLP pattern produced by Alw26I. Case 1-A, Three bands corresponding to the predicted 301,192, and $109 \mathrm{bp}$ fragments were detected. The amplicon digested by MboII gave an incomplete digestion pattern. Case 1-B, Two bands with predicted sizes (265 and $36 \mathrm{bp}$ ) were detected. The amplicon without mutation at $2144 G$ gave this pattern. Case 2-A, One 301 bp band was detected. The amplicon without mutation at $2143 G$ gave this pattern. Case 2-B, The amplicon with a mutation at

A2144G was completely digested by Alw26I, producing the predicted 209, 56, and 36 bp fragments. Case 3-A, The pattern was similar to that of case 2-A. Case 3-B, Four bands corresponding in size to 265, 209, 56, and 36 bp were detected, showing an incomplete digestion pattern.
DNA samples were also prepared from 17 pylori isolates as described above. We designed primers using the $23 \mathrm{~S}$ rRNA gene sequence reported by Hiratsuka (Genebank accession number U27270). The primers were as follows: forward primer, 5'-CTGCATGAATGGCG TAACGAG-3' (complementary to $23 \mathrm{~S}$ rRNA gene sequence from 2047 to 2067), and reverse primer, 5'-GAGCGACCGCCCCAGTCAAA C-3' (complementary to $23 \mathrm{~S}$ rRNA gene sequence from 2327 to 2347), which will generate a 301 bp product. PCR amplifications were performed with Ex-Taq polymerase (Takara, Tokyo, Japan) and a model TP240 PCR thermal cycler (Takara). The amplification reaction mixture $(50 \mu \mathrm{l})$ contained $2.0 \mathrm{mM} \mathrm{MgCl}$, $1.0 \mathrm{U}$ of Ex-Taq polymerase, and $0.5 \mu \mathrm{l}$ of the sample DNA. Cycling conditions were 30 cycles of $94^{\circ} \mathrm{C}$ for one minute, $56^{\circ} \mathrm{C}$ for 30 seconds, $68^{\circ} \mathrm{C}$ for 30 seconds, followed by a final extension step at $68^{\circ} \mathrm{C}$ for seven minutes. The PCR product was resolved on an $8 \%$ polyacrylamide gel and the gel was stained with SYBER Green I nucleic acid gel stain (Molecular Probes, Eugene, Oregon, USA). In order to evaluate our PCR method, we also performed the established PCR method targeting urease $\mathrm{A} .{ }^{10}$

MUTATION ANALYSIS

We analysed mutations in the $23 \mathrm{~S}$ rRNA gene of $H$ pylori by RFLP. Amplicons (PCR amplified DNA fragments) were digested by the restriction enzymes, MboII (Takara) and Alw26I (Fermentas, Vilnius, Lithuania). Mutations create an additional site for digestion by these restriction enzymes: $M b o I I$ for the A2143G mutation and Alw26I for the A2144G mutation. Reaction mixtures $(20 \mu \mathrm{l})$ that contained $6.0 \mathrm{U}$ MboII or $5.0 \mathrm{U}$ Alw26I, $10 \mu \mathrm{l}$ of the PCR product, $2 \mu$ digestion buffer, and $8 \mu \mathrm{l}$ water were incubated at $37^{\circ} \mathrm{C}$ for one hour.

In the case of $H$ pylori isolates with mutations or resistance, DNA samples extracted from each colony were amplified by PCR and analysed for the mutations by RFLP as described above and also by direct sequencing. PCR products were purified with a QIAquick PCR purification kit (Qiagen) followed by cycle sequencing with ABI Prism dRhodamine terminator cycle sequencing ready reaction kit (Applied Biosystems, Foster City, California, USA) according to the manufacturer's protocol. Extension products were purified by ethanol precipitation. Sequence analysis was performed with a genetic analyser (ABI Prism 310; Applied Biosystems).

\section{Results}

PCR AMPLIFICATION OF THE 23S rRNA GENE

We successfully amplified the expected $301 \mathrm{bp}$ fragment in $96 \%(79 / 82)$ of samples; 62 of 65 DNA samples were extracted directly from gastric biopsy specimens and 17 of 17 from $H$ pylori colonies. In two of the three $H$ pylori positive patients in which we failed to amplify the PCR product, the urease A gene was also not amplified. In contrast, in six patients judged as $H$ pylori negative by conventional methods, we could amplify the target DNA from gastric biopsy specimens, whereas only one was positive by PCR directed to urease A (data not shown).

DETECTION OF 23S rRNA GENE MUTATIONS BY PCR-RFLP

In these 79 samples, we analysed mutations of the 23S rRNA gene of $H$ pylori by RFLP. Of the 79 amplicons, four (5\%) gave a mutated RFLP pattern after Alw26I digestion and one (1\%) after $M b o$ II digestion. Two of the four amplicons (nos 49 and 71) were completely cleaved by Alw26I, but the cleavage was incomplete in the other two (nos 51 and 82). The one amplicon digested by $\mathrm{MboII}$ also gave an incomplete cleavage pattern (fig 1 ).

COMPARISON BETWEEN MUTATIONS AND SUSCEPTIBILITY TO CLARITHROMYCIN

We evaluated clarithromycin susceptibility by agar dilution test in 41 samples. All four isolates with the Alw26I cleavage site were clarithromycin resistant. The one with the MboII cleavage site, however, was clarithromycin sensitive by the agar dilution test. The rest of the isolates resistant to either Alw26I or $M b o$ II digestion were clarithromycin sensitive except for one (no 75).

DETECTION OF THE MUTATIONS FROM EACH COLONY BY PCR-RFLP AND DIRECT SEQUENCING In isolates nos 51 and 82 in which Alw26I digestion was incomplete, RFLP patterns varied depending on the individual colony: some colonies showed complete digestion patterns whereas an incomplete pattern was seen in others. In no 82, colonies with a wild type pattern were also detected. Isolates nos 49 and 71 , both showing a complete cleavage pattern on digestion with Alw26I, also contained heterogeneous colonies, although the cleavage 
Table 2 Polymerase chain reaction restriction fragment length polymorphism (PCR-RFLP) patterns from different colonies

\begin{tabular}{|c|c|c|c|c|c|c|c|c|}
\hline \multirow[b]{2}{*}{ Isolate no } & \multicolumn{2}{|c|}{ Patient } & \multirow[b]{2}{*}{ Restriction enzyme } & \multirow[b]{2}{*}{ RFLP pattern } & \multicolumn{3}{|c|}{ RFLP pattern (from each colony) } & \multirow{2}{*}{$\begin{array}{l}\text { Sensitivity to } \\
\text { clarithromycin }\end{array}$} \\
\hline & Age & Sex & & & Complete & Incomplete & No mutation & \\
\hline 49 & 42 & $M$ & Alw26I & Complete & 10 & 2 & 0 & Resistant \\
\hline 71 & 53 & M & Alw26I & Complete & 12 & 4 & 0 & Resistant \\
\hline 51 & 46 & M & Alw26I & Incomplete & 7 & 8 & 0 & Resistant \\
\hline 82 & 44 & $M$ & Alw26I & Incomplete & 10 & 7 & 2 & Resistant \\
\hline 8 & 63 & $M$ & MboII & Incomplete & 0 & 4 & 5 & Sensitive \\
\hline 75 & 47 & $M$ & MboII & - & 0 & 1 & 12 & Resistant \\
\hline
\end{tabular}

Table 3 Direct sequence from different colonies

\begin{tabular}{|c|c|c|c|c|c|c|c|c|}
\hline \multirow[b]{2}{*}{ Isolate no } & \multicolumn{2}{|c|}{ Patient } & \multirow[b]{2}{*}{ Restriction enzyme } & \multirow[b]{2}{*}{ RFLP pattern } & \multicolumn{3}{|c|}{$\begin{array}{l}\text { Direct sequence (from each colony) } \\
\text { A to G mutation }\end{array}$} & \multirow{2}{*}{$\begin{array}{l}\text { Sensitivity to } \\
\text { clarithromycin }\end{array}$} \\
\hline & Age & Sex & & & 2143 & 2144 & No mutation & \\
\hline 49 & 42 & M & Alw26I & Complete & 0 & 4 & 0 & Resistant \\
\hline 71 & 53 & M & Alw26I & Complete & 0 & 7 & 0 & Resistant \\
\hline 51 & 46 & M & Alw26I & Incomplete & 0 & 4 & 2 & Resistant \\
\hline 82 & 44 & M & Alw26I & Incomplete & 0 & 6 & 4 & Resistant \\
\hline 8 & 63 & M & MboII & Incomplete & 3 & 0 & 3 & Sensitive \\
\hline 75 & 47 & M & MboII & - & 4 & 0 & 2 & Resistant \\
\hline
\end{tabular}

RFLP, restriction fragment length polymorphism.

was complete in most of them. In isolate no 8 , which had an incomplete pattern on MboII digestion, an incomplete pattern was shown in four colonies whereas five colonies showed the wild type pattern. In isolate no 75 , which showed clarithromycin resistance despite a normal RFLP pattern, colony analysis disclosed a single colony with an MboII cleavage site (table 2).

In isolates nos 49 and 71 , all colonies were shown to have an A2144G transition mutation by sequence analysis. In isolates nos 51 and 82, colonies with an A2144G mutation and those without any mutation were present. In isolate nos 8 and 75, mixed colonies with an A2143G mutation and those without mutation were detected (table 3). In any event, sequence analysis on individual colonies showed that the mutations involved both copies of the $23 \mathrm{~S}$ rRNA gene simultaneously, excluding the possibility that one of the two copies of the $23 \mathrm{~S}$ rRNA gene is mutated (data not shown). In addition to these mutations, we found others, such as T2183C and T2245C, in many isolates from these Japanese patients. However, these mutations were found mutually in both sensitive and resistant colonies (data not shown).

\section{Discussion}

Clarithromycin is one of the most often used and important antibiotics in eradication treatment for $H$ pylori. As the presence of clarithromycin resistant $H$ pylori may result in eradication failure, it is very important to predict bacterial resistance and establish an accurate susceptibility testing method. Clarithromycin inhibits protein synthesis by binding to the peptidyltransferase loop of $23 \mathrm{~S} \mathrm{rRNA},{ }^{11}$ which has been shown at residues A2058 and A2059 in the 23S rRNA gene of $E$ coli. ${ }^{12}$ When these residues mutate, the affinity of clarithromycin binding to ribosomes is reduced, resulting in the clarithromycin resistance. Versalovic et al ${ }^{9}$ have reported that, in $H$ pylori, transitional mutations (A2143G and A2144G, cognate with $E$ coli $23 \mathrm{~S}$ rRNA positions 2058 and 2059) were associated with clarithromycin resistance. Several reports confirmed that the same mutations are responsible for the resistance. ${ }^{13-18}$

We could detect $H$ pylori infection by amplifying the $23 \mathrm{~S}$ rRNA gene of $H$ pylori using Ex-Taq polymerase in patients with positive $H$ pylori status, except for a few cases. The negative cases may have resulted from sampling errors, because in two thirds of them PCR amplifications targeting urease $\mathrm{A}$ also failed. In contrast, we obtained positive amplifications in several $H$ pylori negative patients by conventional methods. Therefore this PCR method employing Ex-Taq polymerase, which has higher fidelity and efficiency of amplification than conventional Taq polymerases, seems to have comparable or better sensitivity and specificity for the diagnosis of $H$ pylor $i$ than a combination of culture and histological methods.

In addition to its diagnostic merit, it allows us to examine by RFLP and direct sequencing the molecular structure of the 23S rRNA gene that is essential for the macrolide resistance. Of the 79 samples, four $(5 \%)$ were digested by Alw26I and one (1\%) by MboII. This mutation rate was similar to the detection rate of resistant strains reported in other countries. ${ }^{1-5}$ We could not detect the rather rare A2143C mutation, recently reported by Stone et al and Occhialini et al..$^{14} 16^{18}$ In two of the four amplicons digested by Alw26I and the one by MboII, cleavage was not complete, leaving some of the original amplicons undigested. Based on these mixed patterns of RFLP, we suspected that these patients may have been infected with either a mixed population of mutant (clarithromycin resistant) and wild type strains of $H$ pylori or a strain with heterozygosity of the 23S rRNA gene. In order to examine these possibilities, we analysed in $H$ pylori isolates with mutations or resistance the PCR product from each colony by PCR-RFLP and direct sequence. In isolates that were completely digested with Alw26I, most colonies were shown by RFLP analysis to have an A2144G transition mutation, although some of them 
showed a mixed pattern. In isolates incompletely digested by Alw26I or MboII, colonies with the A to $G$ transition mutation at 2143 or 2144 and colonies without mutations were found. Sequence analysis of amplicons from individual colonies confirmed the RFLP results. These results suggest that, in each patient, heterogeneous strains with various genotypes form colonies simultaneously. In metronidazole resistance, co-infection with a population of metronidazole sensitive and resistant strains has been suggested. ${ }^{19} 20 \mathrm{Al}-$ though Versalovic et $a l^{9}$ have reported on one isolate with heterozygosity of the $23 \mathrm{~S}$ rRNA gene, our detailed colony analysis showed that almost all the mutations were homozygous for the $23 \mathrm{~S}$ rRNA gene. In addition, we detected several other mutations such as T2183C and T2245C, which were similarly found in both sensitive and resistant colonies, and hence may represent a local variation of Japanese strains, unrelated to drug resistance.

We found some discrepancy between mutational analysis and susceptibility testing to clarithromycin: all the isolates with an Alw26I digestion pattern were clarithromycin resistant, but the one digested by $M b o$ II was clarithromycin sensitive. In addition, we found one isolate that showed resistance despite having a normal RFLP pattern, although detailed colony analysis disclosed the presence of a small number of resistant strains in this case. Thus the results of mutational analysis correlated well with susceptibility testing in most cases, but it should be noted that some cases may give discordant results when the ratio between the heterogeneous strains is greatly skewed.

We think that our PCR method can offer an accurate and quick way of not only diagnosing $H$ pylori infection but also identifying clarithromycin resistant strains. Although macrolide use may not have been reported accurately by the patients, our data showing the presence of both mutant and wild type $H$ pylori strains in these patients strongly suggest that they were indeed not previously exposed to macrolide antibiotics, because the mutations were fairly stable and not easily reversed. ${ }^{17}$ Spontaneous mutation of a single base is known to occur at a relatively constant rate of $10^{-9} / \mathrm{b}$ ase/cell division. Considering the reported genome size $\left(1.6 \times 10^{6}\right.$ bases/haploid $)$ of $H$ pylori, ${ }^{21}$ the probability of spontaneous mutation occurring in a single bacterial genome is estimated to be $10^{-9} \times 1.6 \times 10^{6} \times 2$. As most of the clarithromycin resistance is caused by point mutation at 2143 and 2144, the probable spontaneous mutation rate at these sites is calculated to be $4.0 \times 10^{-9} /$ cell division. As the number of $H$ pylori is estimated to be $10^{7}-10^{9} / 100 \mu \mathrm{l}$ gastric mucus, ${ }^{22}{ }^{23}$ the total number of bacteria in a stomach may be in the range $10^{9}-10^{11}$, assuming the amount of gastric mucus is limited to $10 \mathrm{ml}$. In addition to those in the mucus, a similar number of bacteria adhere to the mucosa, therefore the total number would be twice that. Therefore it is quite reasonable to assume that between eight and $8 \times 10^{2}$ resistant bacteria emerge after each cell division. Although we do not know exactly how $H$ pylori multiplies in the stomach, the chance of creating a clarithromycin resistant strain with a mutation at either of these two bases should be much higher, as they are not quiescent and will repeat cell division. The mutagenic effect of nitric oxide or an incomplete mismatch repair system in $H_{\text {pylori }}{ }^{21}$ may further increase the mutation rate. Thus it is possible that a small number of clarithromycin resistant strains may emerge spontaneously in the stomach. As they are only a minority of the population, it would be difficult to detect such a small number of mutant bacteria. However, after incidental clarithromycin exposure, these resistant strains will survive and become dominant enough to be detectable by conventional tests. This would explain the apparent increase in clarithromycin resistance. In conclusion, our results suggest that the apparent bacterial resistance to clarithromycin may not be induced but actually result from selection and enrichment of resistant strains by antimicrobial treatment.

We thank Ms S Hiwatashi for excellent technical assistance. This work was supported in part by grants from the Ministry of Education, Science and Culture of Japan. The authors are indebted to Professor J Patrick Barron of the International Medical Communications Center of Tokyo Medical College for reviewing the manuscript.

1 Cayla R, Lamouiliatte H, Megraud F, et al. Primary resistance of Helicobacter pylori strains to metronidazole resistance of Helicobacter pylori strains to metronidazole
and to clarithromycin in France in 1993 [abstract]. Gastroand to clarithromycin in

2 Xia HX, Keane CT, O'Morain CA. Prevalence and stability of clarithromycin resistance in Helicobacter pylori: clinical implications. Am $\mathcal{F}$ Gastroenterol 1994;89:1391.

3 Hachem CY, Clarridge JE, Evans DG, et al. Analysis of pretreatment in vitro microbiology to evaluate eradication of $\mathrm{H}$. pylori in patients with duodenal ulcers. Am $\mathcal{F}$ Gastroenterol 1994;89:1373.

4 van Zwet AA, de Boer WA, Schneeberger PM, et al. Prevalence and primary Helicobacter pylori resistance to mertonidazole and clarithromycin in the Netherlands. Eur f Clin Microbiol Infect Dis 1996;15:861-4.

5 Gotoh A, Kawakami Y, Akahane T, et al. Susceptibility to Helicobacter pylori isolates against agents commonly chemotherapy. Microbiol Immunol 1997;41:7-12.

6 Xia HX, Buckley M, Hyde D, et al. Effects of antibioticresistance on clarithromycin-combined triple therapy for Helicobacter pylori [abstract]. Gut 1995;37(suppl 1):A55.

7 Yousfi MM, el-Zimaty HM, al-Assi MT, et al. MetronidaYousfi $\mathrm{MM}$, el-Zimaty $\mathrm{HM}$, al-Assi MT, et al. Metronida-
zole, omeprazole and clarithromycin: an effective combination therapy for Helicobacter pylori infection. Aliment Phamacol Ther 1995;9:209-12.

8 Moayyedi P, Sahay P, Tompkins DS, et al. Efficacy and optimum dose of omeprazole in a new 1 -week triple regimen to eradicate Helicobacter pylori. Eur f Gastroenterol Hepatol 1995;7:835-40.

9 Versalovic J, Shortridge D, Kibler K, et al. Mutations in 23S rRNA are associated with clarithromycin resistance in Helicobacter pylori. Antimicrob Agents Chemother 1996;40: 477-80.

10 Clayton CL, Kleanthous H, Tabaqchali S. Detection and identification of Helicobacter pylori by the polymerase chain reaction. $\mathfrak{f}$ Clin Pathol $1991 ; \mathbf{4 4}: 515-16$.

11 Goldman RC, Zakula D, Flamm R, et al. Tight binding of clarithromycin, its 14-(R)-hydroxy metabolite, and erythromycin to Helicobacter pylori ribosomes. Antimicrob romycin to Helicobacter pylori rib

12 Moazed D, Noller HF. Chloramphenicol, erythromycin, carbomycin, and vernamycin B protect overlapping sites in the peptidyl transferase region of $23 \mathrm{~S}$ ribosomal RNA. Biochimie 1987;69:879-84.

13 Debets-Ossenkopp YJ, Sparrius M, Kusters JG, et al. Mechanism of clarithromycin resistance in clarithromycin resistance in clinical isolates of Helicobacter pylori. FEMS Microbiol 1996;142:37-42.

14 Stone GG, Shortridge D, Versalovic J, et al. A PCRoligonucleotide ligation assay to determine the prevalence of $23 \mathrm{~S}$ rRNA gene mutations in clarithromycin-resistant Helicobacter pylori. Antimicrob Agents Chemother 1997;41: 712-14.

15 Szczebara F, Dhaenens L, Vincent P, et al. Evaluation of rapid molecular methods fordetection of clarithromycin resistance in Helicobacter pylori. Eur f Clin Microbiol Infect Dis 1997;16:162-4. 
16 Stone GG, Shortridge D, Flamm RK, et al. Identification of 23S rRNA gene mutation in clarithromycin-resistant Helicobacter pylori. Helicobacter 1996;1:227-8.

17 Hulten K, Gibreel A, Skold O, et al. Macrolide resistance in Helicobacter pylori: mechanism and stability in strain from clarithromycin-treated patients. Antimicrob Agents Chemother 1997;41:2550-3.

18 Occhialini A, Uradaci M, Doucet-Populaire $\mathrm{F}$, et al. Macrolide resistance in Helicobacter pylori: rapid detection of point mutations and assays of macrolide binding to ribosomes. Antimicrob Agents Chemother 1997;41:2724-8. 19 Weel JFL, van der Hulst RWM, Gerrits Y, et al. Heterogen-
eity in susceptibility to metronidazole among Helicobacter pylori isolates from patients with gastritis or peptic ulcer disease. f Clin Microbiol 1996;34:2158-62.
20 Jorgensen M, Daskalopoulos G, Warburton V, et al. Multiple strain colonization and metronidazole resistance in Helicobacter pylori infected patients: identification from sequential and multiple biopsy specimens. F Infect Dis 1996;174: $631-5$.

21 Tomb JF, White O, Kerlavege AR, et al. The complete genome sequence of the gastric pathogen Helicobacter pylori. Nature 1997;388:539-47.

22 Furuta T, Kaneko E, Suzuki M, et al. Quantitative study of Helicobacter pylori in gastric mucus by competitive PCR using synthetic DNA fragments. F Clin Microbial 1996;34: $2421-5$.

23 Nowak JA, Forouzandeh B, Nowak JA. Estimates of Helicobacter pylori densities in gastric mucus layer by PCR, histologic examination, and CLO test. Am 7 Clin Pathol 1997; 108:284-8. 